\title{
Propofol reduces hypoxia-induced autophagic cell death through downregulating HIF $1 \alpha$ in alveolar epithelial type II cells of rats
}

\author{
HUI-JIE NING, HONG-BIN YUAN, HAI-TAO XU and XING-YING HE
}

Department of Anesthesiology, Changzheng Hospital, The Second Military Medical University, Shanghai 200003, P.R. China

Received March 25, 2016; Accepted April 10, 2017

DOI: $10.3892 / \mathrm{mmr} .2017 .6697$

\begin{abstract}
Propofol (2,6-diisopropylphenol) exerts protective effects on alveolar epithelial type II (ATII) cells, partly through attenuating hypoxia-induced apoptosis. Autophagy is involved in the activation of apoptosis. Therefore, the present study investigated the modulating effect of propofol against autophagy in ATII cells under hypoxia. Western blot analysis was performed to detect the protein expression of the autophagy molecular marker, microtubule-associated protein 1 light chain 3 (LC3)-II, under various conditions. The effects of propofol on the accumulation of other autophagy-associated proteins and apoptosis-associated proteins were also determined using western blot analysis. The interactions between proteins were determined by co-immunoprecipitation. Apoptosis of the ATII cells was monitored using FITC-conjugated AV/PI staining. Furthermore, hypoxia-inducible factor $1 \alpha$ (HIF $1 \alpha$ ) small interfering (si) RNA was designed to construct si-HIF $1 \alpha$ ATII cells. The efficiency of interference was measured using reverse transcription-quantitative polymerase chain reaction and western blot analyses. Following pre-treatment with propofol, the hypoxia-induced accumulation of LC3-II, HIF $1 \alpha$ and B-cell lymphoma-2 interacting protein 3 (Bnip3) were markedly decreased, accompanied with the activation of mammalian target of rapamycin. In addition, cleaved-poly ADP-ribose polymerase was suppressed, and hypoxia-induced autophagic cell death was inhibited by propofol pre-treatment. HIF $1 \alpha$ was inhibited by si-HIF $1 \alpha$, which simultaneously suppressed Bnip3 and LC3-II under hypoxia. Taken together, propofol reduced hypoxia-induced autophagic cell death through reducing the expression of HIF $1 \alpha$ in ATII cells, indicating
\end{abstract}

Correspondence to: Dr Xing-Ying He or Dr Hong-Bin Yuan, Department of Anesthesiology, Changzheng Hospital, The Second Military Medical University, 415 Fengyang Road, Shanghai 200003, P.R. China

E-mail: hexykxy@126.com

E-mail: 2609232704@qq.com

Key words: propofol, hypoxia, hypoxia-inducible factor $1 \alpha$, Bnip3, alveolar epithelial type II cells a novel strategy for modulating autophagy via propofol in hypoxic ATII cells.

\section{Introduction}

Hypoxic-ischemic pulmonary injury is a common type of pathological damage, and investigations of anesthetics for lung protection have predominantly focused on the perioperative stage. Propofol (2,6-diisopropylphenol) is an intravenous anesthetic, which is used widely in general anesthesia and for sedation in intensive care units (1). Several studies have focused on the protective effect of propofol on organs in vivo (2-4). Propofol prevents lung injury by inhibiting the expression of CD14 and Toll-like receptor 4, and activation of the nuclear factor erythroid 2-related factor 2 pathway $(3,5)$. It exerts anti-inflammatory effects by inhibiting the phosphorylation of p38 mitogen-activated protein kinase, stress activated protein kinase/c-Jun N-terminal kinase, activating transcription factor 2 and c-jun (6), and can exert anti-apoptotic effects by decreasing the accumulation of hypoxia-inducible factor $1 \alpha$ (HIF $1 \alpha$ ), B cell lymphoma-2 (Bcl-2) interacting protein 3 (Bnip3) and cytokines in alveolar epithelial cells (7). Propofol has also been reported to exert an antioxidative effect via its inhibition of inducible nitric oxide synthase in lung L2 cells (8). However, these studies did not distinguish alveolar type I (ATI) from alveolar type II (ATII), particularly in terms of physiological function. ATII cells can synthesize and secrete alveolar surface-active substance, transport water and electrolytes across the membrane, and are involved in oxidative metabolism $(9,10)$. When ATI cells are injured, ATII can proliferate and transform into ATI cells (11). The results of a previous study demonstrated that ATII cells were crucial in the maintenance of physiologic function and the repair of impaired lung tissue (12). Considering the significant differences in physiologic function between ATI and ATII cells, it is important to perform specific respective investigations. Our previous study showed that propofol alleviated hypoxia-induced apoptosis and increased the viability of ATII cells (13). Thus, further protective effects of propofol against pathological stimuli in ATII cells require further investigation.

Autophagy, also termed type II programmed cell death, often coexists with apoptosis and necrosis during hypoxia and ischemia. Under normal conditions, a degree of autophagy contributes to the maintenance of cell homeostasis through the removal of denatured proteins and aging organelles, 
and through the provision of substrate and raw materials for different types of biochemical reactions in cells (14). In the case of adverse pathological stimuli, including hypoxia, autophagic activity increases rapidly to adapt to the changes (15). However, the over-activation of autophagy leads to autophagic cell death. The involvement of autophagy in apoptosis remains controversial (16). It has been reported that apoptosis can be inhibited by the autophagy signaling pathway in lung epithelial cells $(7,17)$. By contrast, autophagy may activate apoptosis indirectly due to the inducible effects on apoptotic signal activation by the nonselective degradation of autophagy (18). Taken together, how to modulate autophagy and subsequently exert promoting effects on cell survival requires elucidation.

It has been demonstrated that autophagy is involved in programmed cell death by regulating the p53-mediated pathway; propofol attenuates cell death through autophagic mechanisms in the rat hippocampus (19). The expression levels of proteins associated with autophagy were found to be induced by propofol treatment in a cellular hypoxia reoxygenation model of human umbilical vein endothelial cells, which revealed the effect of propofol on the autophagy signaling network (20). In addition, our previous study reported the survival-promoting effects of propofol via the inhibition of ATII cell apoptosis (13). At present, the primary mechanism underlying the effect of propofol on ATII cell autophagy remains to be elucidated. The aim of the present study was to investigate the protective effect of propofol on ATII cell autophagy under hypoxia, and examine the underlying mechanisms.

\section{Materials and methods}

Animals. A total of 3 male Sprague-Dawley rats (weight, 150-200 g; age, 3-4 months) were purchased from the Animal Experimental Centre of the Chinese Academy of Sciences (Shanghai, China). They were housed in a cage with an atmosphere of $50 \%$ humidity and a 12-h light/dark cycle at room temperature with an adequate supply of food and water. The present study was approved by the Ethics Committee of Changzheng Hospital, The Second Military Medical University (Shanghai, China).

Reagents. Propofol, DNase, trypsin, heparin sodium, the SDS Gel Preparation kit and N-acetyl-L-cysteine were all purchased from Sigma-Aldrich; Merck Millipore (Darmstadt, Germany). Pentobarbital sodium was from Merck Millipore; DMEM and fetal bovine serum (FBS) were purchased from Gibco; Thermo Fisher Scientific, Inc. (Waltham, MA, USA). Rabbit primary microtubule-associated protein 1 light chain 3 (LC3) polyclonal antibody (cat. no. ab48394), rabbit primary BNIP3 polyclonal antibody (cat. no. ab38621), rabbit primary GABARAP polyclonal antibody (cat. no. ab1398) and mouse primary GAPDH monoclonal antibody (cat. no. ab8245) were all purchased from Abcam (Cambridge, MA,USA).Horseradish peroxidase (HRP)-conjugated anti-rat immunoglobulin $\mathrm{G}$ (IgG; cat. no. sc-2450) was obtained from MR Biotech (Santa Cruz, CA, USA). Protein A/G Agarose and RIPA lysis buffer were from Beyotime Institute of Biotechnology (Haimen, China). The electrophoresis apparatus used in western blot analysis was from Invitrogen; Thermo Fisher Scientific, Inc. 3-MA was purchased from Sigma-Aldrich; Merck Millipore and rapamycin was purchased from Sangon Biotech Co., Ltd. (Shanghai, China).

Isolation and culture of primary ATII cells. The ATII cells were isolated from the rats as described in a previous study (21) with modifications. Briefly, heparin sodium (400 IU/kg) and pentobarbital $(60 \mathrm{mg} / \mathrm{kg})$ were used for rat anesthesia. Under sterile conditions, open pleuroperitoneal cavity surgery of the rats was performed, and the lungs were then flushed with saline and ventilated until they become pale. Bronchoalveolar lavage was performed to perfuse the lungs. Following removal from the body and incubated with trypsin for $30 \mathrm{sec}$, the perfused lungs were incubated with $10 \mathrm{ml}$ of trypsin at $37^{\circ} \mathrm{C}$ for $5 \mathrm{~min}$, followed by the addition of $5 \mathrm{ml}$ trypsin every $5 \mathrm{~min}$ three times. Subsequently, the enzyme reaction was blocked by immersion into DNase containing FBS, and the lungs were removed and sliced into sections of $1 \mathrm{~mm}^{3}$. The digested tissue was agitated at $37^{\circ} \mathrm{C}$ for $5 \mathrm{~min}$ on a shaker and filtered using stainless steel cells strainers. The obtained filtrate was centrifuged at $4^{\circ} \mathrm{C}$ for $10 \mathrm{~min}(800 \mathrm{x} \mathrm{g})$. Following re-suspension in DMEM containing $0.25 \%$ of DNase, $1 \times 10^{6}$ ATII cells were incubated with rat $\mathrm{IgG}$ at $37^{\circ} \mathrm{C}$, which was pre-coated on culture bottles. After $1 \mathrm{~h}$, non-adherent cells were collected, suspended in DMEM containing 20\% FBS, and cultured at $37^{\circ} \mathrm{C}$. The primary culture of ATII cells entered the logarithmic phase on the second day, and cells cultured for $24 \mathrm{~h}$ were used for subsequent experiments.

Propofol treatment. The cells were divided into four groups according to the different treatment regimens: Cells in the control group were cultured under normoxic conditions; cells in the propofol group were pre-treated with propofol (10 or $20 \mu \mathrm{mol} / \mathrm{l}$ ) for $1 \mathrm{~h}$ under normoxic condition, followed by culturing in normoxic conditions for $24 \mathrm{~h}$; cells in the hypoxia group were cultured in normoxic conditions for $1 \mathrm{~h}$ and in $5 \%$ oxygen for $24 \mathrm{~h}$; cells in the hypoxia-propofol group were pre-treated with propofol (10 or $20 \mu \mathrm{mol} / \mathrm{l}$ ) for $1 \mathrm{~h}$ under normoxic conditions, followed by stimulation under hypoxia (5\% oxygen) for $24 \mathrm{~h}$.

HIF $1 \alpha$ siRNA transfection. When the cells were grown to 60-80\% confluence, Lipofectamine 2000 transfection reagent (Invitrogen; Thermo Fisher Scientific, Inc.) was used for transient transfection according to the manufacturer's protocol. The cells were divided into a control group (transfected with scrambled siRNA) and HIF $1 \alpha$ siRNA group. At $48 \mathrm{~h}$ post-transfection, $5 \times 10^{5}$ cells were incubated in normoxia or hypoxia for $24 \mathrm{~h}$, with or without pre-treatment with propofol (20 $\mu \mathrm{mol} / \mathrm{l}$ ), as described above. Scrambled siRNA (forward, 5'-GATCCGCTGATGACCGGAACTTG-3'; reverse, 5'-GCT TTTCCAAAAACTGTGCCAGG-3') and HIF $1 \alpha$ siRNA (forward, 5'-AGAGGUGGAUAUGUGUGGGDTDT-3'; reverse, 5'-GGATCACACACTGTGTCCAGTTT-3') were synthesized by Invitrogen; Thermo Fisher Scientific, Inc.

Western blot analysis. The expression levels of proteins associated with autophagy and apoptosis were determined using western blot analysis. The cell contents were extracted with 


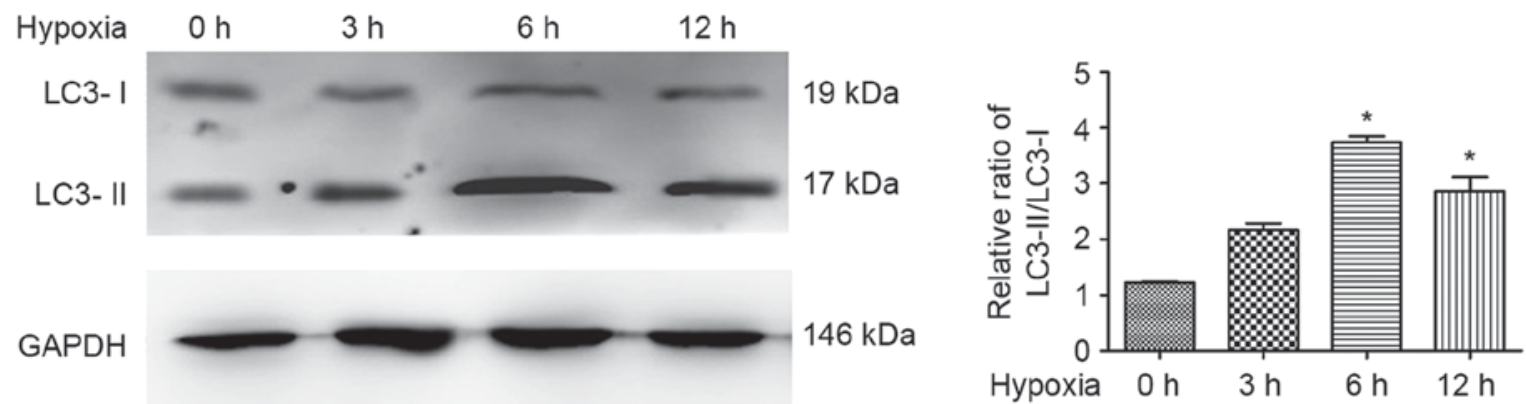

Figure 1. Expression levels of LC3 in ATII cells under exposure to hypoxia. Expression levels of LC3 (LC3-I and LC3-II) in ATII cells exposed to hypoxia $\left(5 \% \mathrm{O}_{2}\right)$ for 3,6 and $12 \mathrm{~h}$ were detected using western blot analysis using anti-LC3 antibodies. GAPDH was used as an internal control, with no difference observed between the samples. ${ }^{*} \mathrm{P}<0.05$, compared with the control $(0 \mathrm{~h})$. ATII, alveolar epithelial type II; LC 3 , microtubule-associated protein 1 light chain 3 .

an extraction kit (KGP250; Nanjing Keygen Biotech. Co., Nanjing, China) and incubated for $30 \mathrm{~min}$ at $4^{\circ} \mathrm{C}$, followed by sonication and centrifugation $\left(5,000 \mathrm{x}\right.$ g for $30 \mathrm{~min}$ at $\left.4^{\circ} \mathrm{C}\right)$. The supernatants were collected immediately and stored at $-70^{\circ} \mathrm{C}$ for later experiments. Protein concentrations were determined using a Takara Bicinchoninic Protein Assay kit (cat. no. T9300A; Takara Biotechnology, Co., Ltd., Dalian, China), according to the manufacturer's instructions. Proteins $(20 \mu \mathrm{g})$ were isolated on a $6 \%$ SDS-PAGE gel and transferred onto nitrocellulose membranes (Bio-Rad Laboratories, Inc., Hercules, CA, USA) for sample analysis. The membranes were blocked with 5\% BSA and incubated with the primary antibodies (1:1,000; all described in the 'Reagents' section) for $16 \mathrm{~h}$ at $4^{\circ} \mathrm{C}$, followed by incubation with HRP-conjugated secondary antibodies $(1: 10,000)$ for $1 \mathrm{~h}$ at room temperature. ECL reagents were used to detect the blotting signals.

Co-immunoprecipitation assay. For co-immunoprecipitation, the protein samples $(600 \mu \mathrm{g})$ were mixed with rabbit anti-rat IgG (1 $\mu \mathrm{g}$ powder; cat. no. A3231) and Protein A/G Agarose $(20 \mu \mathrm{l})$, and incubated for 1.5 hat $4^{\circ} \mathrm{C}$. Following centrifugation at $2,500 \mathrm{x}$ g for $5 \mathrm{~min}$ at $4^{\circ} \mathrm{C}, 1 \mu \mathrm{g}$ anti-Bcl-2 primary antibody (1:500; cat. no. 15071; Cell Signaling Technology, Inc., Danvers, MA, USA) was added to the supernatant and incubated overnight at $4^{\circ} \mathrm{C}$, following which incubation was continued with another $40 \mu \mathrm{l}$ Protein A/G Agarose for $2 \mathrm{~h}$ at $4^{\circ} \mathrm{C}$. The supernatant was removed carefully following centrifugation at $9,500 \mathrm{x} \mathrm{g}$ for $15 \mathrm{~min}$ at $4^{\circ} \mathrm{C}$. The protein-bead was then washed with washing solution I containing $50 \mathrm{mM}$ Tris, $150 \mathrm{mM} \mathrm{NaCl}$ and $0.1 \% \mathrm{NP}-40$ (pH 7.5) and washing solution II comprising $10 \mathrm{mM}$ Tris ( $\mathrm{pH} 7.5$ ) three times, respectively. The sediments were collected and boiled in loading buffer for $5 \mathrm{~min}$, prior to loading $20 \mu \mathrm{g}$ total proteins/lane for separation using $10 \%$ SDS-PAGE.

Reverse transcription-quantitative polymerase chain reaction (RT-qPCR) analysis. Total RNA was extracted from the ATII cells using TRIzol reagent (Promega Corp., Madison, WI, USA) according to the manufacturer's instruction. The RT-qPCR analysis was performed in the 7500 Fast Real Time PCR system (Applied Biosystems; Thermo Fisher Scientific, Inc.). Quantification of gene expression was performed using the $2^{-\Delta \Delta \mathrm{Cq}}$ method (22), with $\beta$-actin as an endogenous control. The total reaction system (final reaction volume, $25 \mu \mathrm{l}$; cat. no. RR036Q; Takara Biotechnology, Co., Ltd.) of RT-qPCR included $2 \mu \mathrm{l}$ of the cDNA template, $0.5 \mu \mathrm{l}$ of the upstream primer, $0.5 \mu \mathrm{l}$ of the downstream primer, $12.5 \mu \mathrm{l}$ of the SYBR green super mix, $0.5 \mu \mathrm{l}$ of Takara Ex Taq HS (5 U/ $\mu \mathrm{H}), 0.5 \mu \mathrm{l}$ of PrimeScript RT Enzyme Mix II and $8.5 \mu \mathrm{l}$ of RNase Free $\mathrm{dH}_{2} \mathrm{O}$. The primer sequences used in the present study were as follows: $\beta$-actin, forward 5'-CTATCGGCAATGAGC GGTTC-3' and reverse 5'-GATCTTGATCTTCATGGTGCT AGG-3'. HIF $1 \alpha$, forward 5'-AACAAGCCGGGGGAGGAC GA-3' and reverse 5'-GCCACACTGCGGCTGGTCT-3'. The PCR program was as follows: $50^{\circ} \mathrm{C}$ for $2 \mathrm{~min}, 95^{\circ} \mathrm{C}$ for $5 \mathrm{~min}$, followed by 40 cycles at $95^{\circ} \mathrm{C}$ for $15 \mathrm{sec}$ and $60^{\circ} \mathrm{C}$ for $45 \mathrm{sec}$.

FITC-conjugated AV/PI staining. Apoptosis was detected using FITC-conjugated AV/PI staining. The cells were stained with PI solution $(20 \mu \mathrm{g} / \mathrm{ml})$ and mixed with FITC-conjugated AV for $15 \mathrm{~min}$ at room temperature in the dark. The cells were then washed with $400 \mu 1$ ice-cold PBS. The samples were measured within $1 \mathrm{~h}$ using a FACScan flow cytometer (BD Biosciences, Franklin Lakes, NJ, USA) equipped with CellQuest Pro software version 5.1. For each sample 10,000 events were collected.

\section{Results}

Hypoxia induces autophagy in ATII cells in a time-dependent manner. As previous investigations revealed that cell autophagy was induced by hypoxia (23), the present study investigated the expression levels of LC3 in response to hypoxic exposure in ATII cells. The results of the western blot analysis revealed that LC3-II accumulated and the LC3-II/LC3-I ratio was significantly increased in the hypoxia-treated ATII cells, compared with that in the control cells, exhibiting a peak at $6 \mathrm{~h}$ of hypoxia treatment (Fig. 1). This indicated that the induced autophagy was caused by hypoxia treatment in the ATII cells in a time-dependent manner.

Propofol dose-dependently attenuates hypoxia-induced autophagy in ATII cells. To examine the effect of propofol on hypoxia-induced autophagy in ATII cells, the present study evaluated the accumulation of LC3 in cells with or without pre-treatment with propofol using western blot analysis. As shown in Fig. 2, hypoxia exposure significantly enhanced the accumulation of LC3-II and increased the LC3-II/LC3-I ratio, whereas the enhanced accumulation was significantly reduced when 

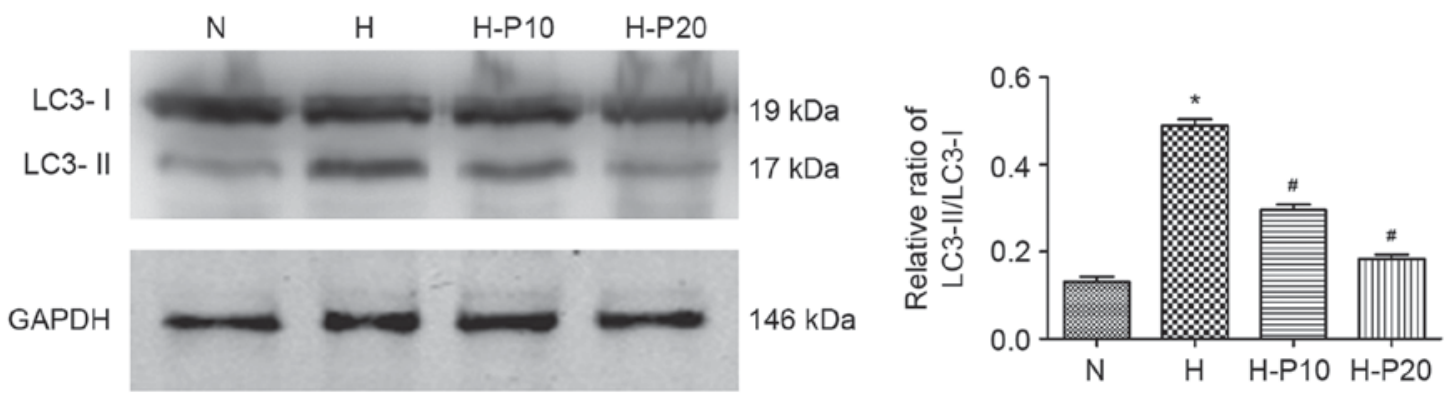

Figure 2. Expression levels of LC3 in hypoxia-exposed ATII cells pre-treated with propofol. Expression levels of LC3 (LC3-I and LC3-II) in ATII cells were detected using western blot analysis using anti-LC3 antibodies. GAPDH was used as an internal control. No difference was observed between the samples. ${ }^{*} \mathrm{P}<0.05$, compared with the control $(\mathrm{N})$; ${ }^{*} \mathrm{P}<0.05$, compared with the control $(\mathrm{H}) . \mathrm{N}$, normoxia; H, hypoxia $\left(5 \% \mathrm{O}_{2}\right)$; H-P10, pre-treated with propofol $(10 \mu \mathrm{M})$ and hypoxia $\left(5 \% \mathrm{O}_{2}\right) ; \mathrm{H}-\mathrm{P} 20$, pre-treated with propofol $(20 \mu \mathrm{M})$ and hypoxia $\left(5 \% \mathrm{O}_{2}\right)$. ATII, alveolar epithelial type II; LC3, microtubule-associated protein 1 light chain 3.

A
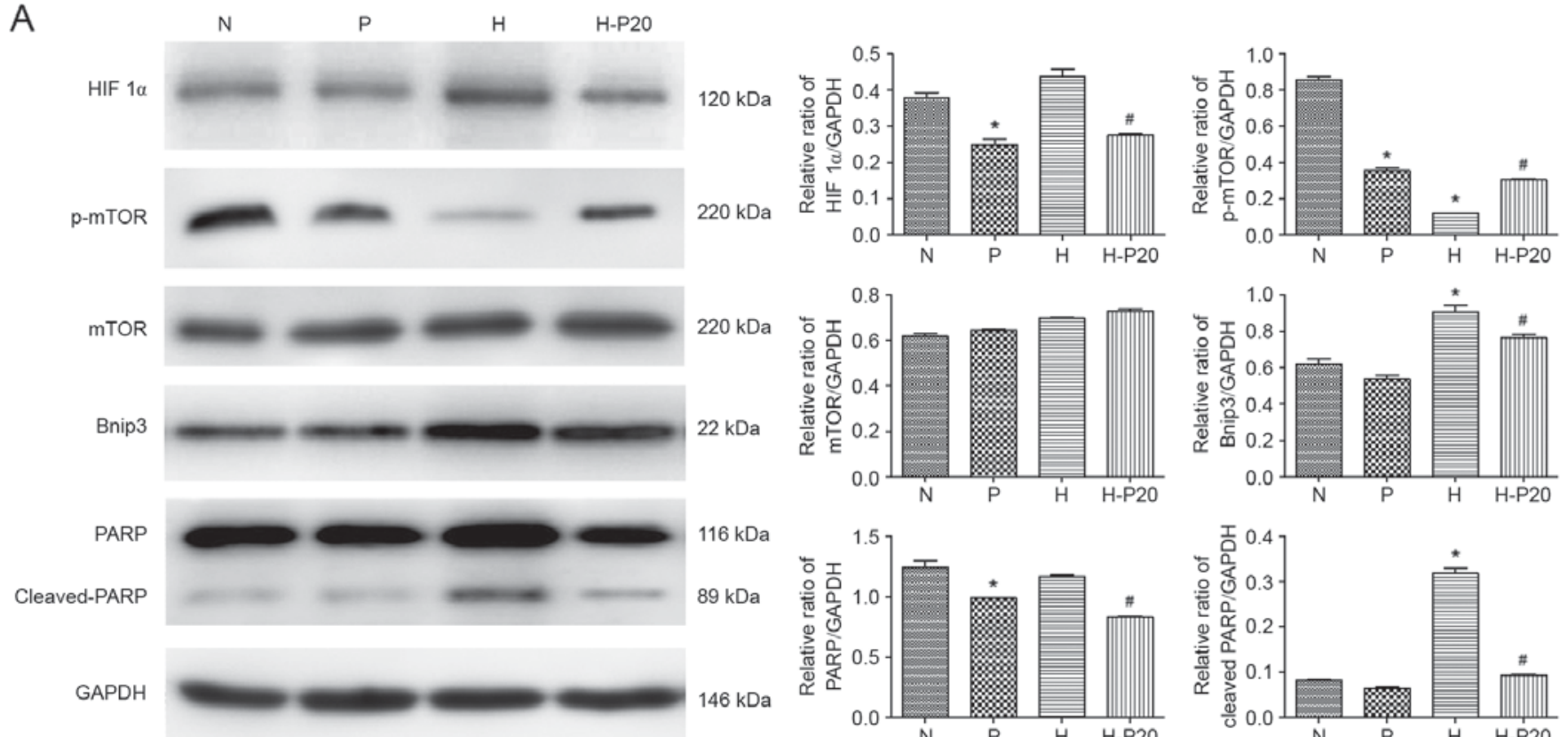

B
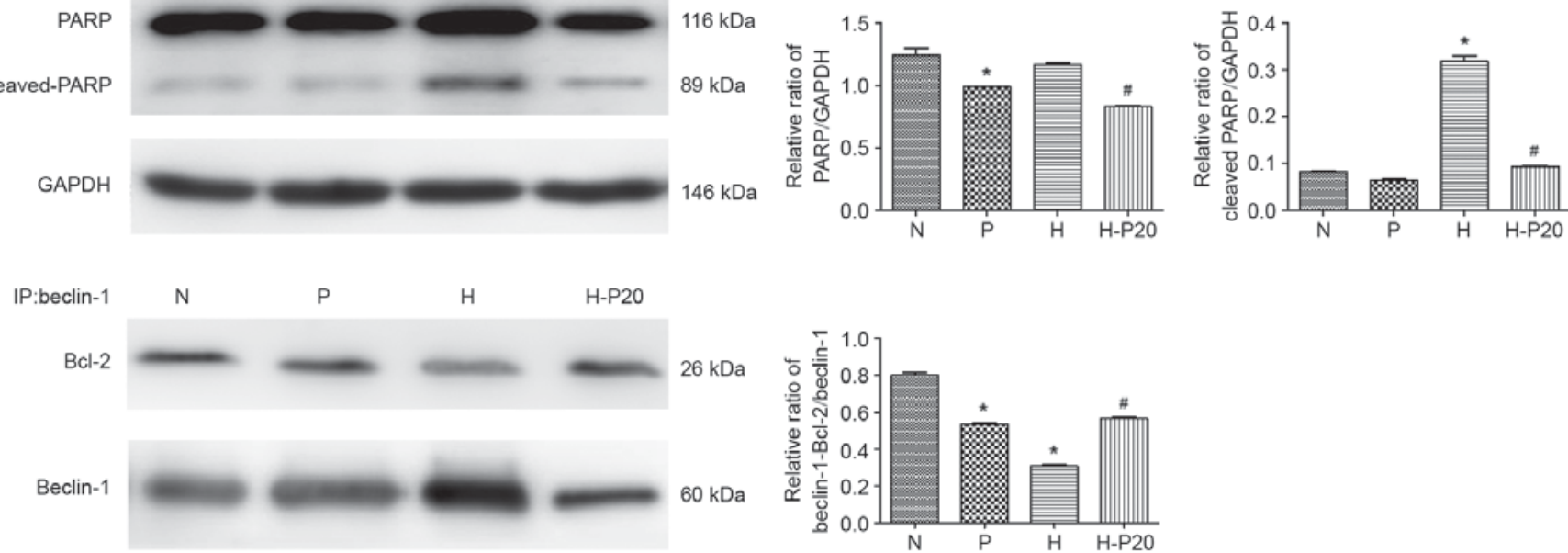

Figure 3. Expression levels of proteins associated with autophagy under hypoxia. (A) Expression levels of autophagy-associated proteins in alveolar epithelial type II cells were detected using western blot analysis with specific antibodies against each protein. (B) Immunoprecipitation was used to detect the Bcl-2/Beclin-1 interaction. Total cell lysates were incubated with anti-Beclin-1 antibodies. The Bcl-2/Beclin-1 interaction and total input of Beclin-1were detected using western blot analysis using anti-Bcl-2 and anti-Beclin-1 antibodies, respectively. ${ }^{*} \mathrm{P}<0.05$, compared with the control $(\mathrm{N}){ }^{*} \mathrm{P}<0.05$, compared with the control $(\mathrm{H})$. N, normoxia; P, pre-treated with propofol $(20 \mu \mathrm{M}) ; \mathrm{H}$, hypoxia $\left(5 \% \mathrm{O}_{2}\right) ; \mathrm{H}-\mathrm{P} 20$, pre-treated with propofol $(20 \mu \mathrm{M})$ and hypoxia $(5 \%$ $\mathrm{O}_{2}$ ). ATII, LC3, microtubule-associated protein 1 light chain 3; HIF 1 $\alpha$, hypoxia-inducible factor $1 \alpha$; mTOR, mammalian target of rapamycin; p-mTOR, phosphorylated mTOR; Bcl-2, B-cell lymphoma-2; Bnip3, Bcl-2 interacting protein 3; PARP, poly ADP-ribose polymerase.

the cells were pre-treated with propofol, particularly at $20 \mu \mathrm{M}$. These results indicated that propofol prohibited hypoxia-induced autophagy of ATII cells in a dose-dependent manner.

Effect of propofol on the expression of autophagy-associated proteins under hypoxic conditions. Autophagy is predominantly regulated by two types of complex: mammalian target of rapamycin (mTOR) and Beclin-1. To examine how propofol regulates hypoxia-induced autophagy, the present study analyzed the expression of several autophagy-associated proteins involved in these pathways in the ATII cells. As shown in Fig. 3A, the expression levels of HIF $1 \alpha$ and Bnip3 were increased in the cells under hypoxic conditions. In addition, when the cells were pre-treated with hypoxia, the levels 

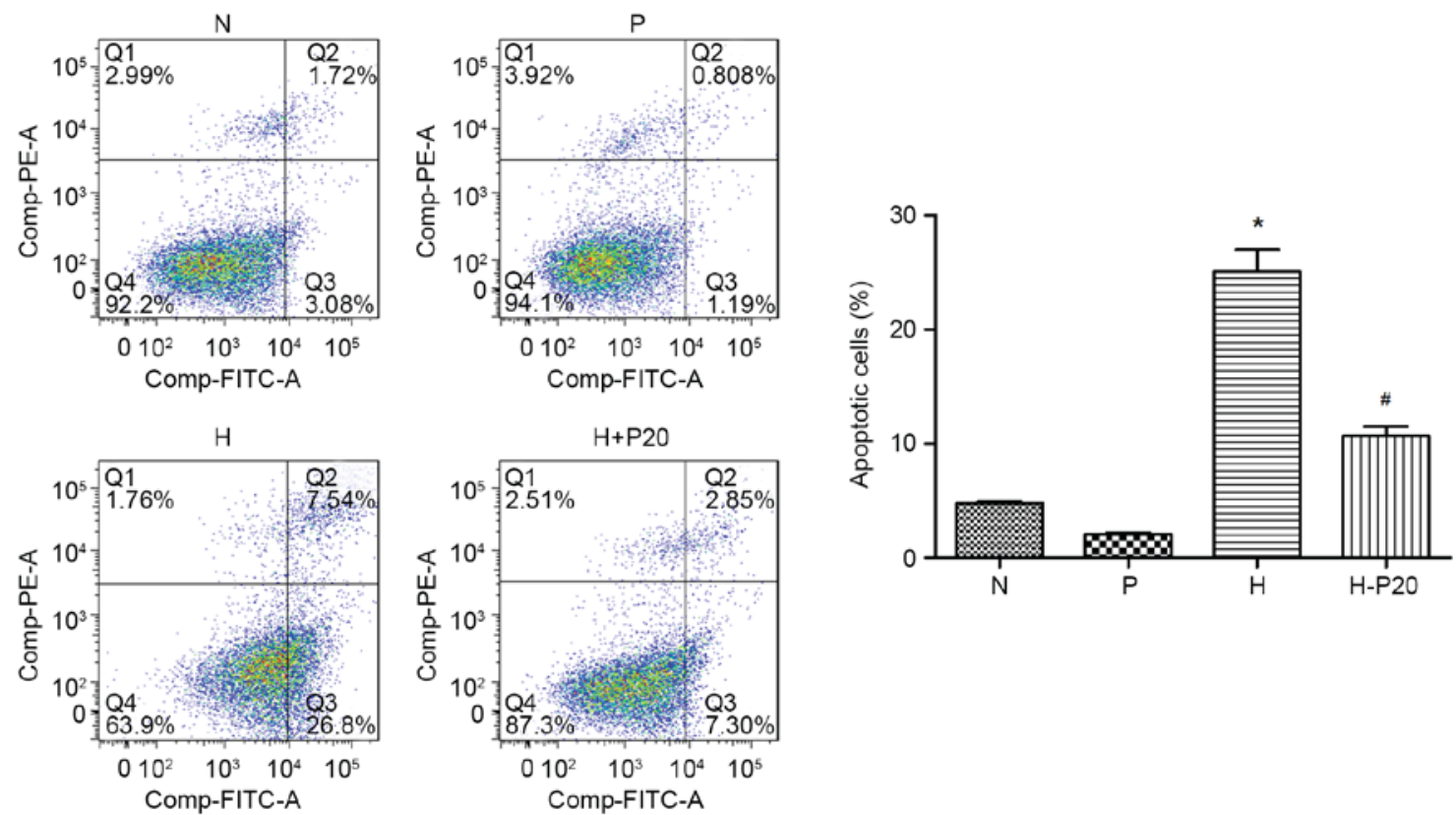

Figure 4. Apoptosis of alveolar epithelial type II cells detected using Annexin V/PI flow cytometric analysis. " $\mathrm{P}<0.05$, compared with the control (N); ${ }^{~} \mathrm{P}<0.05$, compared with the control $(\mathrm{H})$. N, normoxia; P, pre-treated with propofol $(20 \mu \mathrm{M}) ; \mathrm{H}$, hypoxia $\left(5 \% \mathrm{O}_{2}\right) ; \mathrm{H}-\mathrm{P} 20$, pre-treated with propofol $(20 \mu \mathrm{M})$ and hypoxia $\left(5 \% \mathrm{O}_{2}\right)$.

of p-mTOR and Beclin-1 were significantly reduced. However, pre-treatment with propofol in the hypoxia-treated ATII cells significantly inhibited the hypoxia-induced expression of HIF $1 \alpha$ and Bnip3, and upregulated the expression of p-mTOR. The results of the immunoprecipitation assay revealed that hypoxia markedly decreased the interaction between Beclin-1 and $\mathrm{Bcl}-2$, whereas the decreased interaction between Beclin-1 and Bcl-2 induced by hypoxia was markedly attenuated by propofol (Fig. 3B).

Effect of propofol on hypoxia-induced apoptosis in ATII cells. It was previously reported that propofol can reduce hypoxia-induced apoptosis (13). Therefore, the present study examined cell apoptosis and the expression of cleaved-poly ADP-ribose polymerase (PARP) in the different groups. As shown in Fig. 3A, the expression level of cleaved-PARP was markedly increased when the cells were under hypoxic conditions, however, the increased expression of cleaved-PARP was reduced when the cells were pre-treated with propofol. These results were consistent with changes in autophagy-associated proteins in response to diverse conditions. The results of the flow cytometry supported the conclusion that hypoxic condition caused cell apoptosis. Compared with cells in normal conditions, hypoxia notably promoted the apoptotic cell ratio, whereas pre-treatment with propofol reversed the hypoxia-induced apoptosis (Fig. 4).

Knockdown of HIF $1 \alpha$ inhibits hypoxia-induced autophagy in ATII cells. To further verify whether HIF $1 \alpha$ and Bnip3 regulate autophagyin ATII cells under hypoxia, specific siRNA targeting HIF $1 \alpha$ was constructed. As shown in Fig. 5A and B, the mRNA and protein expression levels of HIF $1 \alpha$ were markedly decreased. The expression levels of Bnip3 and LC3-II were also evaluated in cells treated with hypoxia. The results of the western blot analysis showed that the hypoxia-induced increase in the expression levels of Bnip3 and LC3-II was suppressed by the inhibition of HIF $1 \alpha$ (Fig. 5C). Consequently, hypoxia-induced autophagy was ameliorated by HIF $1 \alpha$ gene deletion. These data suggested that the hypoxia-induced autophagy and apoptosis were reduced by pre-treatment with propofol, which was partially dependent on the expression level of HIF $1 \alpha$.

\section{Discussion}

LC3, which is necessary for the formation of the autophagosome, is modified by the yeast autophagy associated gene 8 modification system. Following the synthesis of LC3, there are two forms, termed LC3-I and LC3-II. Among these, LC3-II is the final form of LC3 and is involved in the formation of the autophagosome. Therefore, the level of LC3-II and the LC3-II/LC3-I ratio can be detected to indicate autophagic activity (24,25). In the present study, LC3-II was regarded as an autophagy molecular marker and it was found that propofol attenuated the hypoxia-induced accumulation of LC3-II in ATII cells. The anti-apoptotic effects of propofol on ATII cells under hypoxic exposure have been reported previously (13), and these findings were supported by those of the present study using flow cytometry. To further investigate whether propofol promotes cell viability associated with the regulation of autophagy, the present study also detected the expression of the apoptosis-associated protein, PARP, in parallel with autophagy-associated proteins. As shown in Fig. 3, the hypoxia-induced upregulation of cleaved-PARP was markedly reduced by propofol, which occurred with the inhibition of autophagy. These results demonstrated that propofol increased the cell survival rate and may rely on the regulation of autophagy.

Cells respond to hypoxia by activating HIF $1 \alpha$ (26). As the target gene of HIF $1 \alpha$, Bnip3 has been implicated in the 
A

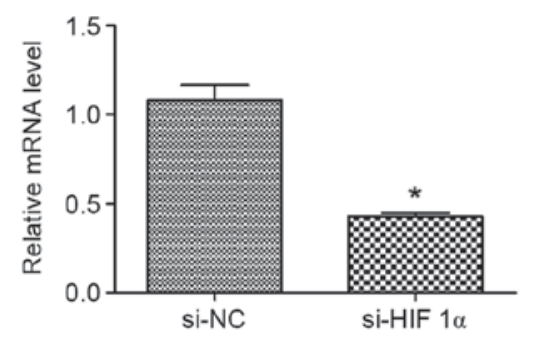

C

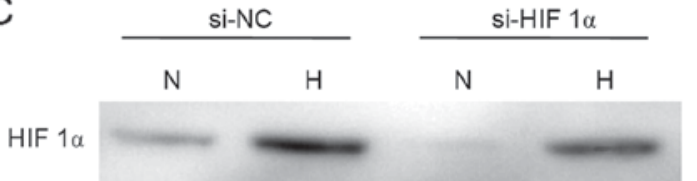

Bnip3
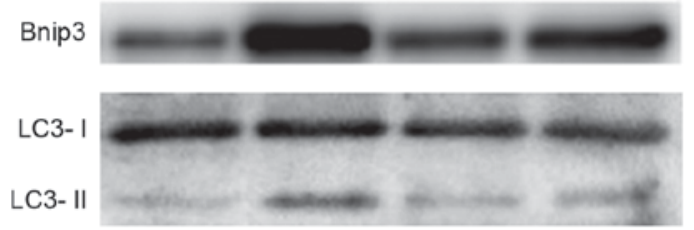

$19 \mathrm{kDa}$

GAPDH
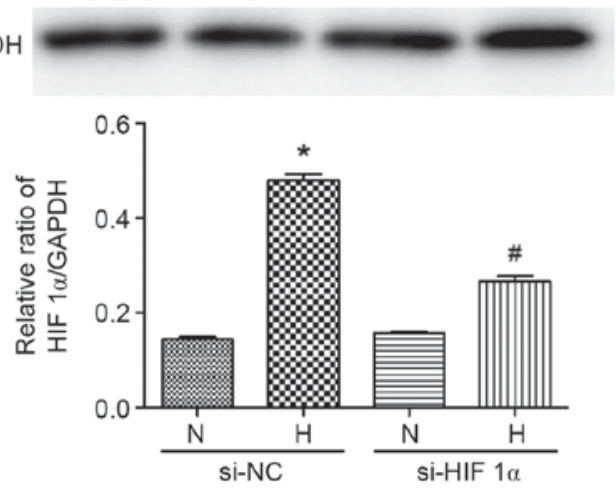

$17 \mathrm{kDa}$

B
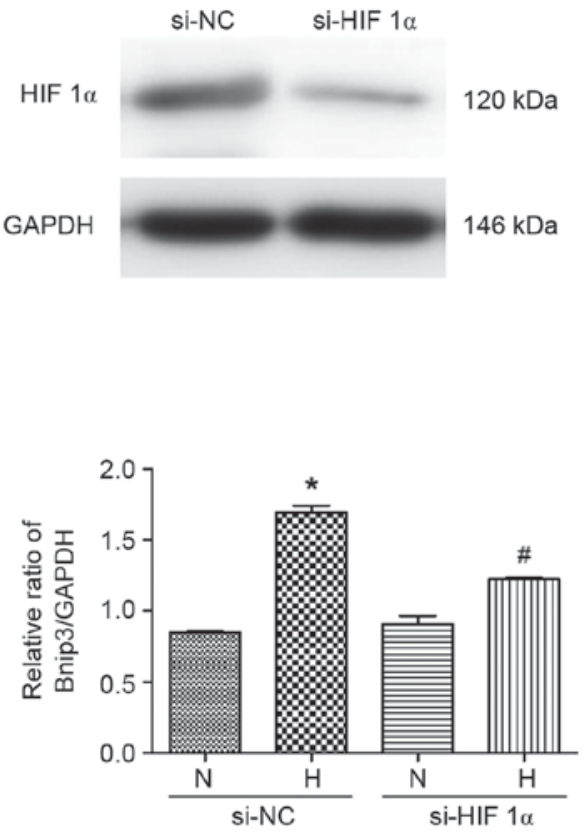

$146 \mathrm{kDa}$

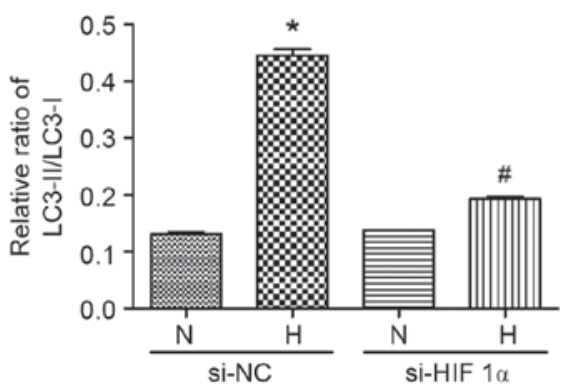

Figure 5. Specific HIF $1 \alpha$ siRNA target attenuates hypoxia-induced effects in ATII cells. (A) Transfection efficiency of si-HIF 1 $\alpha$ was verified using reverse transcription-quantitative polymerase chain reaction analysis. ${ }^{*} \mathrm{P}<0.05$, compared with control si-NC. (B) Transfection efficiency of si-HIF $1 \alpha$ was verified using western blot analysis. (C) Expression levels of Bnip3 and LC3 in ATII cells pre-treated with si-HIF 1 $\alpha$ transfection and exposed to hypoxia were detected using western blot analysis. " $\mathrm{P}<0.05$, compared with the control si-NC (N); ${ }^{\#} \mathrm{P}<0.05$, compared with the control si-NC $(\mathrm{H})$. N, normoxia; $\mathrm{P}$, pre-treated with propofol $(20 \mu \mathrm{M}) ; \mathrm{H}$, hypoxia $\left(5 \% \mathrm{O}_{2}\right) ; \mathrm{H}-\mathrm{P} 20$, pre-treated with propofol $(20 \mu \mathrm{M})$ and hypoxia $\left(5 \% \mathrm{O}_{2}\right)$. ATII, alveolar epithelial type II; LC3, microtubule-associated protein 1 light chain 3; HIF 1 $\alpha$, hypoxia-inducible factorl $\alpha$; Bnip3, Bcl-2 interacting protein 3; si-, small interfering RNA; NC, negative control.

induction of autophagy and may be regulated by hypoxia (27). Autophagy is predominantly regulated by two types of complexes upstream of ATG, the mTOR complex and the Beclin-1 complex. Previous studies have shown that the phosphorylation of mTOR prevented formation of the autophagosome, thus, negatively mediating autophagy $(28,29)$. Rheb, a Ras-related small GTPase, is a key upstream activator of mTOR. Bnip3, which is induced by hypoxia, can directly bind to Rheb (30). As a consequence, Bnip3 leads to the negative regulation of mTOR. Beclin-1 directly interacts with class III phosphatidylinositol 3-kinase (PI3KC3) to induce autophagy, and the inhibition or loss of lipid kinase components inhibits autophagy (29,31). Beclin-1 also interacts with Bcl-2 family proteins, including Bcl-2. The binding of Bcl-2 with Beclin-1 prevents the formation of the Beclin-1-PI3KC3 complex and eventually inhibits autophagy (29). In the present study, it was found that hypoxia-induced autophagy was associated with the accumulation of HIF $1 \alpha$ and Bnip3, the deactivation of $\mathrm{m}-\mathrm{TOR}$, and attenuation of the interaction between Beclin-1 and $\mathrm{Bcl}-2$. However, pre-treatment with propofol altered this status, increasing the level of p-mTOR, promoting the interaction between Beclin-1 and Bcl-2, and reducing the levels of HIF $1 \alpha$ and Bnip3 (Fig. 3A and B). These results suggested that propofol negatively regulated hypoxia-induced autophagy via Bnip3 through the m-TOR-dependent and Beclin-1-dependent pathways, and that HIF $1 \alpha$ may act as a regulator in this process.

HIF $1 \alpha$ is important in the regulation of cell proliferation, apoptosis, autophagy and glucose metabolism under hypoxic conditions. Previously, suppressing the expression of HIF $1 \alpha$ by silencing HIF $1 \alpha$ in glioblastoma U87 cells was shown to inhibit the proliferation of U87 cells (32). Glucose metabolism is also promoted by HIF $1 \alpha$ under hypoxic conditions, which protects liver cells from damage (33). HIF $1 \alpha$ regulates apoptosis and autophagy via HIF $1 \alpha$-microRNA feedback in response to hypoxia $(15,34)$, and it has been reported that HIF $1 \alpha$ is essential to the pro-apoptotic response of ATII cells upon hypoxia (35). In the present study, HIF $1 \alpha$ was knocked down using siRNA, and it was found that the hypoxia-induced increase in the expression levels of Bnip3 and LC3-II was 
inhibited in these cells (Fig. 5C), which indicated that HIF 10 may modulate autophagic activity in ATII cells under hypoxia by regulating the downstream gene, Bnip3.

In conclusion, the results of the present study demonstrated that propofol was important in the inhibition of the hypoxia-induced autophagy. In addition, HIF $1 \alpha$ was a crucial regulator of autophagy in ATII cells via Bnip3, through m-TOR-dependent and Beclin-1-dependent pathways. These results provide novel understanding of the effect of propofol in modulating autophagic cell death via HIF $1 \alpha$-Bnip3 in hypoxia, and revealed the potential clinical role of propofol in the treatment of hypoxic-ischemic pulmonary injury.

\section{Acknowledgements}

This study was supported by the National Natural Science Foundation of China (grant no. 81100049), the Shanghai Municipal Science and Technology Commission medical guide project (grant no. 15411966000) and the Shanghai Pujiang Program (grant no. 15PJD003).

\section{References}

1. Li C, Xu M, Wu Y, Li YS, Huang WQ and Liu KX: Limb remote ischemic preconditioning attenuates lung injury after pulmonary resection under propofol-remifentanil anesthesia: A randomized controlled study. Anesthesiology 121: 249-259, 2014.

2. Bae HB, Li M, Lee SH, Jeong CW, Kim SJ, Kim HS, Chung SS and Kwak SH: Propofol attenuates pulmonary injury induced by collapse and reventilation of lung in rabbits. Inflammation 36 : 680-688, 2013

3. Yao W, Luo G, Zhu G, Chi X, Zhang A, Xia Z and Hei Z: Propofol activation of the Nrf2 pathway is associated with amelioration of acute lung injury in a rat liver transplantation model. Oxid Med Cell Longev 2014: 258567, 2014

4. Hatakeyama N and Matsuda N: Alert cell strategy: Mechanisms of inflammatory response and organ protection. Curr Pharm Des 20: 5766-5778, 2014

5. Ma L, Wu XY, Zhang LH, Chen WM, Uchiyama A, Mashimo T and Fujino Y: Propofol exerts anti-inflammatory effects in rats with lipopolysaccharide-induced acute lung injury by inhibition of CD14 and TLR4 expression. Braz J Med Biol Res 46: 299-305, 2013.

6. Wei L, Matsumoto H and Yamaguchi H: Propofol attenuates lipopolysaccharide-induced monocyte chemoattractant protein-1 production through p38 MAPK and SAPK/JNK in alveolar epithelial cells. J Anesth 27: 366-373, 2013.

7. Yeh CH, Cho W, So EC, Chu CC, Lin MC, Wang JJ and Hsing CH Propofol inhibits lipopolysaccharide-induced lung epithelial cell injury by reducing hypoxia-inducible factor-1alpha expression. Br J Anaesth 106: 590-599, 2011.

8. Tsai YC, Huang CC, Chu LM and Liu YC: Differential influence of propofol on different cell types in terms of the expression of various oxidative stress-related enzymes in an experimental endotoxemia model. Acta Anaesthesiol Taiwan 50: 159-166, 2012.

9. Heberlein W, Wodopia R, Bärtsch P and Mairbäurl H: Possible role of ROS as mediators of hypoxia-induced ion transport inhibition of alveolar epithelial cells. Am J Physiol Lung Cell Mol Physiol 278: L640-L648, 2000.

10. Matthay MA, Folkesson HG and Clerici C: Lung epithelial fluid transport and the resolution of pulmonary edema. Physiol Rev 82: 569-600, 2002.

11. Clegg GR, Tyrrell C, McKechnie SR, Beers MF, Harrison D and McElroy MC: Coexpression of RTI40 with alveolar epithelial type II cell proteins in lungs following injury: Identification of alveolar intermediate cell types. Am J Physiol Lung Cell Mol Physiol 289: L382-L390, 2005.

12. Ghosh MC, Gorantla V, Makena PS, Luellen C, Sinclair SE, Schwingshackl A and Waters CM: Insulin-like growth factor-I stimulates differentiation of ATII cells to ATI-like cells through activation of Wnt5a. Am J Physiol Lung Cell Mol Physiol 305: L222-L228, 2013.
13. He XY, Shi XY, Yuan HB, Xu HT, Li YK and Zou Z: Propofol attenuates hypoxia-induced apoptosis in alveolar epithelial type II cells through down-regulating hypoxia-inducible factor-1 $\alpha$. Injury 43: 279-283, 2012.

14. Rabinowitz JD and White E: Autophagy and metabolism. Science 330: 1344-1348, 2010.

15. Sun Y, Xing X, Liu Q, Wang Z, Xin Y, Zhang P, Hu C and Liu Y: Hypoxia-induced autophagy reduces radiosensitivity by the HIF-1 $\alpha / \mathrm{miR}-210 / \mathrm{Bcl}-2$ pathway in colon cancer cells. Int J Oncol 46: 750-756, 2015.

16. Yousefi $\mathrm{S}$ and Simon HU: Apoptosis regulation by autophagy gene 5. Crit Rev Oncol Hematol 63: 241-244, 2007

17. Guo XG, Ji TX, Xia Y and Ma YY: Autophagy protects type II alveolar epithelial cells from Mycobacterium tuberculosis infection. Biochem Biophys Res Commun 432: 308-313, 2013.

18. Thorburn J, Horita H, Redzic J, Hansen K, Frankel AE and Thorburn A: Autophagy regulates selective HMGB1 release in tumor cells that are destined to die. Cell Death Differ 16: 175-183, 2009.

19. Cui DR, Wang L, Jiang W, Qi AH, Zhou QH and Zhang XL: Propofol prevents cerebral ischemia-triggered autophagy activation and cell death in the rat hippocampus through the NF- $\mathrm{KB} / \mathrm{p} 53$ signaling pathway. Neuroscience 246: 117-132, 2013.

20. Chen Z, Hu Z, Lu Z, Cai S, Gu X, Zhuang H, Ruan Z, Xia Z, Irwin MG, Feng D and Zhang L: Differential microRNA profiling in a cellular hypoxia reoxygenation model upon posthypoxic propofol treatment reveals alterations in autophagy signaling network. Oxid Med Cell Longev 2013: 378484, 2013.

21. Dobbs LG, Gonzalez R and Williams MC: An improved method for isolating type II cells in high yield and purity. Am Rev Respir Dis 134: 141-145, 1986.

22. Livak KJ and Schmittgen TD: Analysis of relative gene expression data using real-time quantitative PCR and the 2(-Delta Delta C(T)) Method. Methods 25: 402-408, 2001.

23. Hu YL, Jahangiri A, De Lay M and Aghi MK: Hypoxia-induced tumor cell autophagy mediates resistance to anti-angiogenic therapy. Autophagy 8: 979-981, 2012.

24. Mizushima N: Methods for monitoring autophagy. Int J Biochem Cell Biol 36: 2491-2502, 2004.

25. Mizushima N, Yoshimori T and Levine B: Methods in mammalian autophagy research. Cell 140: 313-326, 2010.

26. Bellot G, Garcia-Medina R, Gounon P, Chiche J, Roux D, Pouysségur $\mathrm{J}$ and Mazure NM: Hypoxia-induced autophagy is mediated through hypoxia-inducible factor induction of BNIP3 and BNIP3L via their BH3 domains. Mol Cell Biol 29: 2570-2581, 2009.

27. Zhang J and Ney PA: Role of BNIP3 and NIX in cell death, autophagy, and mitophagy. Cell Death Differ 16: 939-946, 2009.

28. Jung CH, Jun CB, Ro SH, Kim YM, Otto NM, Cao J, Kundu M and Kim DH: ULK-Atg13-FIP200 complexes mediate mTOR signaling to the autophagy machinery. Mol Biol Cell 20: 1992-2003, 2009

29. Noh HS, Shin IW, Ha JH, Hah YS, Baek SM and Kim DR: Propofol protects the autophagic cell death induced by the ischemia/reperfusion injury in rats. Mol Cells 30: 455-460, 2010.

30. Li Y, Wang Y, Kim E, Beemiller P, Wang CY, Swanson J, You M and Guan KL: Bnip3 mediates the hypoxia-induced inhibition on mammalian target of rapamycin by interacting with Rheb. J Biol Chem 282: 35803-35813, 2007.

31. Wirth M, Joachim J and Tooze SA: Autophagosome formation-the role of ULK1 and Beclin1-PI3KC3 complexes in setting the stage. Semin Cancer Biol 23: 301-309, 2013.

32. Shen SH, Kwan AL, Chen YY and Wang ZX: Effect of silencing HIF-1 $\alpha$ on proliferation, invasion and migration of glioblastoma U87 cells. Neurol Sci 34: 365-371, 2013

33. Zhuonan Z, Sen G, Zhipeng J, Maoyou Z, Linglan Y, Gangping W, Cheng J, Zhongliang M, Tian J, Peijian Z and Kesen X: Hypoxia preconditioning induced HIF-1 $\alpha$ promotes glucose metabolism and protects mitochondria in liver I/R injury. Clin Res Hepatol Gastroenterol 39: 610-619, 2015.

34. Liu Y, Nie H, Zhang K, Ma D, Yang G, Zheng Z, Liu K, Yu B, Zhai C and Yang S: A feedback regulatory loop between HIF-1a and miR-21 in response to hypoxia in cardiomyocytes. FEBS Lett 588: 3137-3146, 2014

35. Krick S, Eul BG, Hänze J, Savai R, Grimminger F, Seeger W and Rose F: Role of hypoxia-inducible factor-1alpha in hypoxia-induced apoptosis of primary alveolar epithelial type II cells. Am J Respir Cell Mol Biol 32: 395-403, 2005. 